\title{
La conservación de la lápida de Pakal a seis décadas de su descubrimiento
}

Rogelio Rivero Chong

El 27 de noviembre [de 1952] se alzó la lápida esculpida, mediante gatos de automóvil colocados en las esquinas y encima de troncos de árboles, después de ardua labor de 24 horas consecutivas en la que cooperaron todos los trabajadores y mi colega César Sáenz. Debajo de la lápida esculpida apareció la cavidad del sarcófago [...] (Ruz 2007: 203).
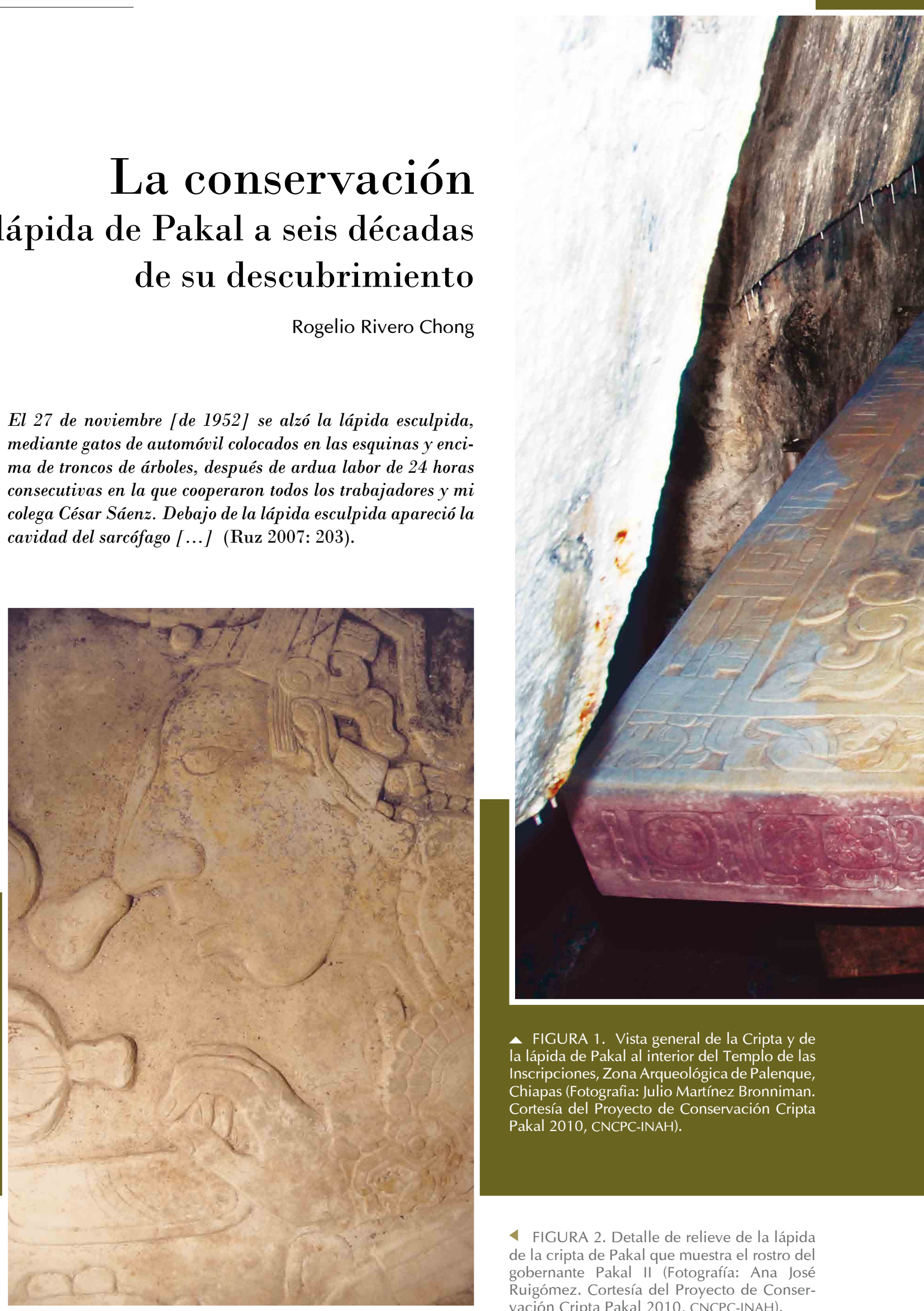

- FIGURA 1. Vista general de la Cripta y de

la lápida de Pakal al interior del Templo de las Inscripciones, Zona Arqueológica de Palenque, Chiapas (Fotografia: Julio Martínez Bronniman. Cortesía del Proyecto de Conservación Cripta Pakal 2010, CNCPC-INAH).

4 FIGURA 2. Detalle de relieve de la lápida de la cripta de Pakal que muestra el rostro del gobernante Pakal II (Fotografía: Ana José Ruigómez. Cortesía del Proyecto de Conservación Cripta Pakal 2010, CNCPC-INAH). 


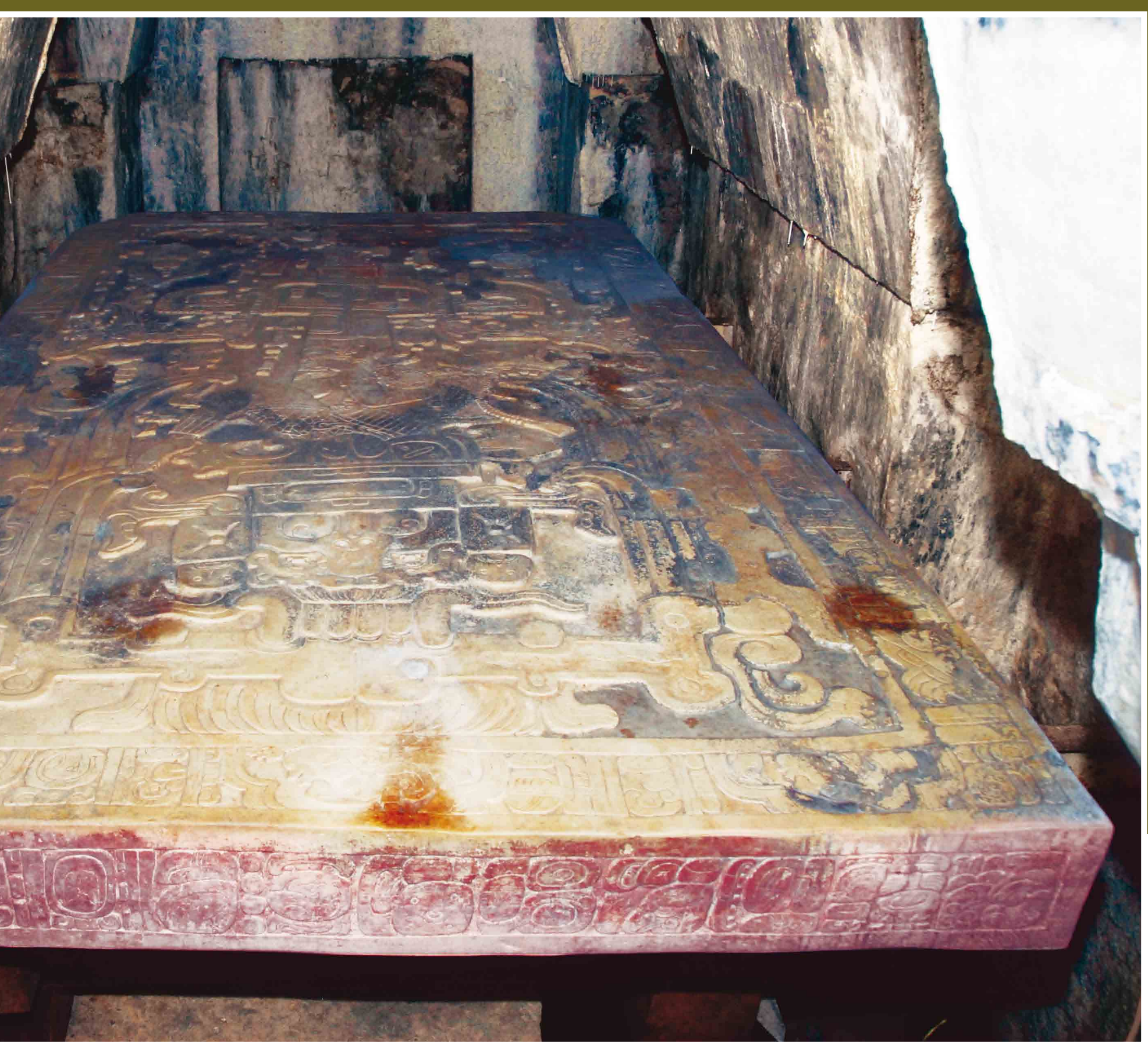

on estas palabras el doctor Alberto Ruz L'Huillier describió uno de los hallazgos más importantes y espectaculares de la arqueología americana: la tumba de K'inich Janaab Pakal II (603-683 d.C.), el gobernante maya que marcó el apogeo de la urbe de Palenque durante el periodo Clásico. La emotividad de la narrativa no fue gratuita: hasta ese momento, la lápida -un monolito de roca caliza de $3.79 \mathrm{~m}$ de largo por 2.20 de ancho y $0.25 \mathrm{~m}$ de espesor (Figura 1), decorado con imágenes en bajo-relieve alusivas a una representación mítica de Pakal (Figura 2)- había permanecido 12 siglos cubriendo el sepulcro ubicado en el interior del Templo de las Inscripciones en Palenque. Con el fin de proseguir con la investigación de uno de los contextos funerarios de mayor riqueza material y documental de Mesoamérica, el doctor Ruz coordinó el levantamiento de la lápida, la cual fue finalmente soportada sobre vigas de hierro. Este arreglo permaneció in situ durante más de un lustro, periodo en el que tanto la lápida como los relieves de estucos que decoran la cripta han sido motivo de interpretación arqueológica y de labores de mantenimiento para prolongar su preservación en un ambiente adverso por sus altos índices de humedad relativa. 
En la actualidad, la Coordinación Nacional de Conservación del Patrimonio Cultural del Instituto Nacional de Antropología e Historia (CNCPC INAH), bajo la gestión de la licenciada Lilia Rivero Weber, a través de la Subdirección de Conservación del Patrimonio Cultural desarrolla el Proyecto de Conservación de la Cripta de Palenque, una iniciativa interdisciplinaria integrada por el arqueólogo Arnoldo González (director del Proyecto Arqueológico de Palenque INAH), el doctor José Ortega (investigador de la Subdirección de Laboratorios y Apoyo Académico-INAH) y el restaurador Rogelio Rivero (subdirector de Conservación de la CNCPCINAH). Como parte de este proyecto se ha asumido la gran responsabilidad de garantizar la conservación de la lápida de Pakal, atendiendo el grave problema de corrosión de las vigas que le sirven de soporte.

Entre las actividades realizadas hasta el momento destacan el registro y levantamiento de información contextual, la protección de los relieves en estuco adosados a los muros, el registro gráfico y fotográfico especializado de cada uno de los elementos de la cripta, así como el análisis de la lápida y del espacio arquitectónico mediante GPR (Ground Penetration Radar), una técnica de avanzada en exploración no invasiva, que ha permitido analizar el estado físico del conjunto (Figura 3). La combinación de desarrollo tecnológico, análisis especializado y colaboración inter institucional ha permitido evaluar las alternativas de conservación a futuro de la lápida, incluyendo la pertinencia de su reubicación sobre el sarcófago.

A seis décadas de su levantamiento, el 13 de julio de este año, la lápida de la cripta de Palenque fue nuevamente elevada tras una ardua, planificada y coordinada jornada de trabajo que evocaba aquella descrita por el doctor Ruz. Después de procesos de limpieza y protección en la superficie pétrea, se implementó un sistema hidráulico de elevación bajo la asesoría del ingeniero Roberto Sán-

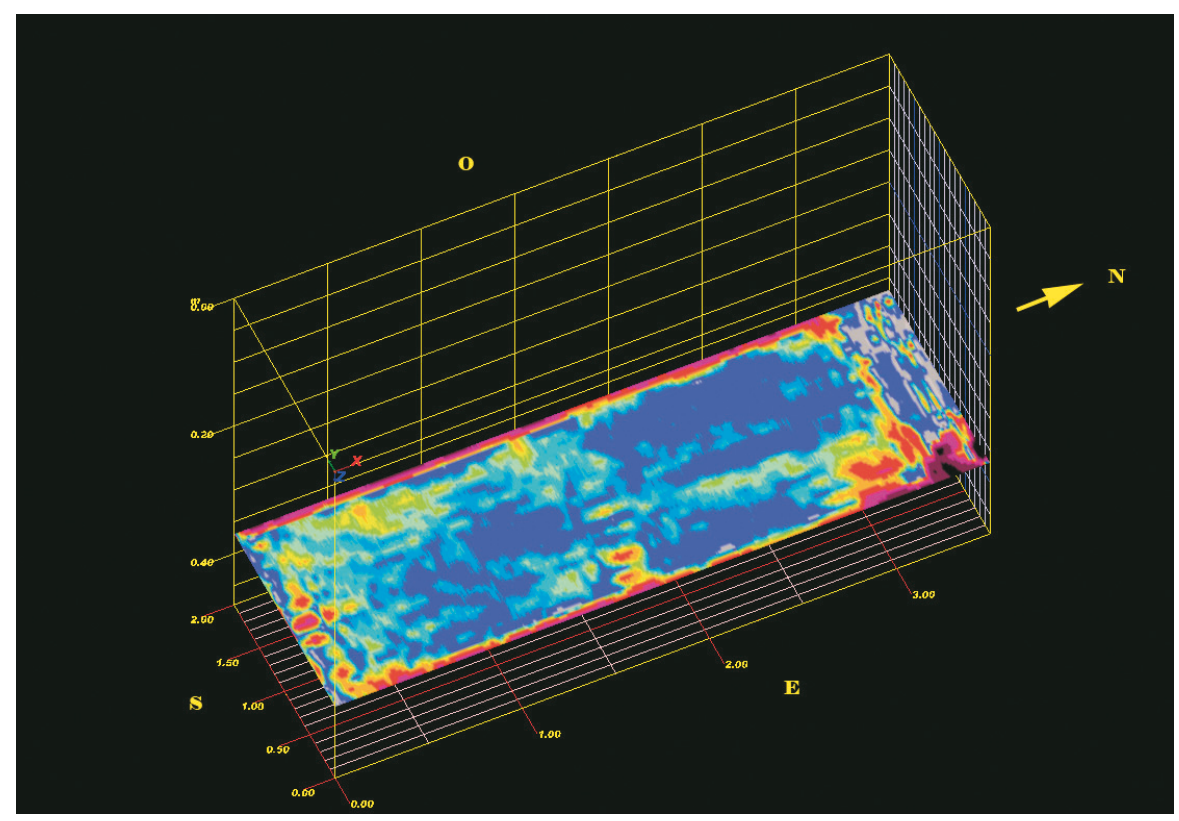

FIGURA 3. Radargrama 3D resultado de la prospección con el GPR en la lápida de Pakal, en el que se observan las diferentes densidades pétreas y la ausencia de deterioros físicos (Imagen de José Ortega. Cortesía del Proyecto de Conservación Cripta Pakal 2010, CNCPC-INAH).

chez (Instituto de Ingeniería-UNAM), que permitió retirar los elementos de hierro ya corroídos y proporcionar estabilidad a la masa de aproximadamente seis toneladas (Figura 4).

Habrá que esperar las siguientes etapas del Proyecto de Conservación

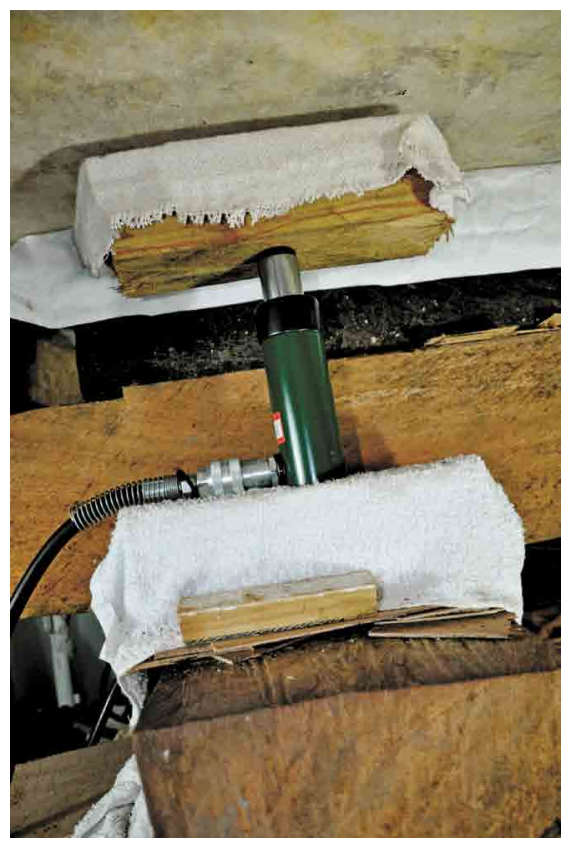

FIGURA 4. Sistema hidráulico utilizado para el movimiento de alzado de lápida, con la asesoría del Ingeniero Roberto Sánchez del Instituto de Ingeniería de la UNAM. (Fotografía: Rogelio Rivero. Cortesía de Proyecto de Conservación Cripta Pakal 2010, CNCPC-INAH).
Cripta de Palenque para compartir los avances generados hasta ahora; baste señalar que la información obtenida apunta a una reconfiguración de los actuales conocimientos que tenemos sobre el Templo de las Inscripciones de Palenque y la cripta de Pakal. Así, la conservación y la arqueología vuelven a unirse, tanto para iluminarnos sobre el pasado prehispánico de México como para guiarnos en las posibilidades de la transmisión de su legado hacia el futuro.

\section{Referencias}

Ruz L'Huillier, Alberto 2007 (1954) "Exploraciones en Palenque: 1952", en Roberto García Moll, (comp.), Palenque, 1947-1958, MéxiCo, Biblioteca INAH, 180-245. 